\title{
Incidence des paramètres hydriques sur le développement des cals d'Hevea brasiliensis en culture in vitro *
}

\author{
H Etienne, P Montoro, MP Carron ** \\ IRCA-CIRAD, Laboratoire BIOTROP-GERDAT, BP 5035, Avenue du Val de Montferrand, \\ 34032 Montpellier Cedex, France
}

(Reçu le 5 juillet 1990; accepté le 26 décembre 1990)

\begin{abstract}
Résumé - La quantification des paramètres hydriques des cals d'Hevea brasiliensis et de leur environnement, au cours du processus d'embryogenèse somatique, met en évidence des situations de stress à différents niveaux : lors de la mise en culture et des jours qui lui succèdent, au niveau de l'humidité relative de l'atmosphère du récipient et du potentiel hydrique du milieu de culture. La réactivité des tissus et l'induction embryogène sont nettement améliorées par le conditionnement hydrique de l'explant initial (assèchement partiel pendant 5-10 min sous un flux d'air), le maintien d'une hygrométrie proche de la saturation et la stabilisation du potentiel hydrique du milieu à un niveau élevé $(-0,7 \mathrm{MPa})$. Des résultats similaires sont obtenus par l'incorporation de $10^{-7} \mathrm{M}$ d'acide abscissique au milieu de culture dès la phase d'induction des embryons somatiques.

Ces effets sont reliés à l'acquisition par le cal d'un statut hydrique bien déterminé, mettant en relief une meilleure hydratation des tissus (fort potentiel hydrique et forte teneur en eau relative), qui apparaît donc indispensable à l'expression de l'embryogenèse somatique. L'analyse de la consommation en azote, potassium et phosphore du milieu témoigne d'une stimulation de l'absorption minérale, chez les cals embryogènes, probablement favorisée par un état physiologique optimal.
\end{abstract}

\section{Hevea brasiliensis / paramètre hydrique / enbryogenèse somatique / nutrition minérale}

\begin{abstract}
Summary - The effect of water parameters on the development of Hevea brasiliensis calli in in vitro culture. The use of micropropagation methods in hevea culture, especially somatic embryogenesis, would improve intraclonal homogeneity as well as vigour and productivity of trees. However, difficulties encountered in the setting up of somatic embryogenesis with hevea led to the study of a number of parameters which are particularly important to the sucess of this technique. The quantification of water parameters of Hevea brasiliensis calli and their environment during the somatic embryogenesis process revealed stress at different levels, at the beginning of culture and during the days which followed related to the relative humidity of vessel atmosphere and the water potential of the culture medium. The delay in mineral absorption and callogenesis of the internal tegument of immature seeds was related to the adjustment period of the intern tegument water potential to that of the medium (table 1). Tissue growth and embryogenic induction were distinctly improved by water conditioning of the initial explant (table II) (partial drying under air flow for 5-10 min). A close relationship was demonstrated between the evolution of water potentials of the medium and callus depending on the relative humidity level in the culture vessel. Keeping the relative humidity close to saturation stimulated an increase in callus water content and callus relative water content associated
\end{abstract}

\footnotetext{
* Article présenté dans le cadre des activités du Groupe d'étude de physiologie de l'arbre

** Corresfondance et tirés à part
} 
with higher embryogenic calli frequency (fig 2). On culture, only the embryogenic calli retained a high water potential ( $-0.9 \mathrm{MPa}$ ) identical to that of the medium (fig 3). Renewing the medium enhanced embryogenic induction (table III). The medium water potential appeared as an important culture parameter: at a high level ( $-0.7 \mathrm{MPa}$ ) it strongly stimulated embryogenic calli initiation (fig 4). These effects are related to a clear water status, with better tissue hydration (high water potential and high relative water content), which thus appears necessary for somatic embryogenesis. similar results were obtained with an early addition of abscissic acid whose optimal concentration (10-7 M) stimulated embryogenic calli formation and the acquisition of this specific water status. Analysis of nitrogen, potassium and phosphorus revealed stimulation of mineral uptake from the medium by the embryogenic calli. This was probably enhanced by optimal physiological conditions (fig 5). The present study demonstrates that hevea callus is a system which is very sensitive to environmental changes: callus browning and inhibition of the embryogenic process provide evidence of this. Hydric regulation of the callus appeared to be very limited. To avoid stress it is therefore necessary to work in optimal conditions for water availability in the vessel atmosphere and culture medium.

Hevea brasiliensis / water parameters / somatic embryogenesis / mineral nutrition

\section{INTRODUCTION}

L'Hevea brasiliensis est la source quasiexclusive de caoutchouc naturel; la consommation annuelle mondiale devrait atteindre 5000000 t en 1990/1991 (Rapport de la banque mondiale sur les produits de base; Marchés tropicaux et méditerranéens, 10 mars 1989) soit une part minimale de $30 \%$ de l'ensemble des caoutchoucs consommés (Compagnon, 1986). Cette culture relativement récente a été nettement améliorée au début du siècle par l'utilisation de greffés, en remplacement des semis présentant une très grande hétérogénéité et en l'absence d'une technique opérationnelle de bouturage.

Dans les années 1970-1980 les progrès de la culture in vitro ont apporté un nouvel espoir de mettre au point une technique de multiplication végétative complète qui permettrait, chez l'hévéa, d'améliorer l'homogénéïté des plantations clonales et surtout d'éviter la baisse de vigueur et de production liée au greffage et au vieillissement du matériel vététal sélectionné (Carron et al, 1989).

L'embryogenèse somatique est tout à fait adaptée à ces objectifs, par son fort potentiel de multiplication et son caractère rajeunissant. Si elle a été obtenue à plusieurs reprises et de façon répétitive chez l'hévéa (Chen et al, 1979; Wan et al, 1982; Carron et Enjalric, 1985), elle n'est cependant pas réellement maîtrisée, qu'il s'agisse du taux d'embryogenèse ou surtout du développement en plantules des embryons formés.

La maîtrise d'un phénomène aussi complexe que l'embryogenèse somatique, c'est-à-dire l'obtention en quantité de plants parfaitement conformes, nécessite sans doute le développement de recherches de base destinées à mettre en relief l'effet des différents paramètres physico-chimiques du milieu sur l'évolution des tissus végétaux. Ainsi, après avoir étudié les polyamines (El Hadrami et al, 1989a; El Hadrami et al, 1989b) l'évolution de la stucture histologique (MichauxFerrière et Carron, 1989) et l'influence de l'atmosphère gazeuse sur l'induction de l'embryogenèse somatique chez l'Hevea brasiliensis (Auboiron et al, 1990), nous présentons ici une étude sur l'incidence des paramètres hydriques, du milieu et de l'atmosphère de culture, sur ceux du matériel végétal. Quelques auteurs ont déjà mis en évidence l'influence du potentiel hydrique du milieu de culture sur le statut hydri- 
que des cals (Kimball et al, 1975; Chandler et al, 1987; Newton et al, 1989a). De même, il a été démontré chez les cals de riz (Lai et Liu, 1988) et de tabac (Brown et Thorpe, 1980; Hammersley-Straw et Thorpe, 1988) qu'un stress hydrique était favorable à la néoformation de tiges via l'acquisition d'un statut hydrique spécifique du matériel végétal. Toutefois, bien que la formation d'embryons somatiques soit parfois favorisée par un faible potentiel osmotique du milieu (Imamura et Harada, 1980; Litz et Conover, 1983; Brown et al, 1989) ou qu'une forte humidité de l'atmosphère de culture soit nécessaire à la formation de cellules embryogènes par les cals d'hévéa (Auboiron et al, 1990), aucune relation entre le statut hydrique de l'environnement de culture et celui d'un cal n'a jamais encore été mise en évidence pour la réussite de l'embryogenèse somatique. Dans ce but, la quantification des caractéristiques hydriques au cours de la culture devrait permettre de mieux comprendre l'influence de l'humidité de l'air, dans le récipient de culture, et de la disponibilité de l'eau, dans le milieu, sur la réactivité des tissus végétaux au cours des processus de callogenèse et d'initiation de l'embryogenèse. En outre, l'effet d'un apport en acide abscissique $(A B A)$ sur l'état hydrique des cals sera étudié, en référence au rôle qu'on lui accorde dans la résistance des tissus végétaux aux stress environnementaux et en particulier aux stress hydriques (Loveys et al, 1975; Abou-Mandour et Hartung, 1986; Guerrero et Mullet, 1986).

\section{MATÉRIEL ET MÉTHODES}

\section{Culture}

Le tégument interne de graine immature (provenant de fruits âgés de 8-10 semaines après anthèse, clone PB 260) est découpé en 20 frag- ments; ces fragments, ultérieurement nommés "explants" dans le texte, développent un cal lorsqu'ils sont mis en culture sur un milieu de Murashige et Skoog (1962) modifié, contenant $234 \mathrm{mmol}^{-1} \mathrm{I}^{-1}$ de saccharose, $9 \mu \mathrm{mol} . \mathrm{I}^{-1}$ d'acide 3,4-dichlorophénoxy-acétique (3,4-D), $9 \mu \mathrm{mol}$. I $^{-1}$ de benzylaminopurine (BAP), ainsi que 30 $\mu$ mol..$^{-1} \mathrm{~d}^{\prime} \mathrm{AgNO}_{3}$ et $2 \mathrm{~g} \mathrm{l}^{-1}$ de gelrite (Carron et Enjalric, 1985; Auboiron et al, 1990).

Certaines potentialités embryogènes du cal sont visibles dès le $15^{\mathrm{e}} \mathrm{j}$ (Michaux-Ferrière et Carron, 1989), mais leur expression nécessite un repiquage vers le $23^{\mathrm{e}} \mathrm{j}$ suivant la mise en culture initiale $\left(J_{23}\right)$, sur le même milieu additionné de $50 \mu \mathrm{mol} . \mathrm{I}^{-1}$ de spermidine.

Un second repiquage est effectué à $J_{46}$, sur un milieu sans $\mathrm{AgNO}_{3}$ ni spermidine et dont les concentrations en 3,4-D et BAP sont abaissées à $0,9 \mu \mathrm{mol} . \mathrm{I}^{-1}$, pour favoriser le développement des embryons.

Toute la culture se déroule à l'obscurité, à une température de $27^{\circ} \mathrm{C}$.

\section{Assèchement par flux d'air}

Les explants fraîchement prélevés, déposés sur une plaque de verre sous une hotte à flux laminaire, sont déshydratés partiellement par un flux d'air de $4,5 \mathrm{~m} . \mathrm{s}^{-1}$ d'une humidité relative de $44 \%$ \pm 2 et sous une température de $23^{\circ} \mathrm{C}$; cela pendant $20,90,300$ et $600 \mathrm{~s}$. Hors expérience, le temps habituellement appliqué pour la préparation des explants avant mise en culture est de $90 \mathrm{~s}$ environ.

\section{Contrôle de l'humidité relative du récipient de culture}

La culture témoin est réalisée en tube de $150 \times$ $25 \mathrm{~mm}$ fermé par un bouchon en polycarbonate, ce qui permet d'obtenir une humidité relative (HR) de l'atmosphère du récipient de culture proche de la saturation (la déshydratation du milieu de culture dans de telles conditions ne dépasse généralement pas $2 \%$ en $23 \mathrm{j}$ de culture).

Le contrôle de l'hygrométrie est obtenu par l'application d'un flux d'air dont l'humidité relative est stabilisée selon la méthode mise au point par Greenspan (1977), à raison de 3 renouvelle- 
ments de l'atmosphère du récipient de culture par minute : le bullage dans des solutions saturées de $\mathrm{KNO}_{3}$ et de $\mathrm{KCl}$ permet d'obtenir, à $27^{\circ} \mathrm{C}$, des $H R$ de $77 \% \pm 2$ et $70 \% \pm 2$ respectivement (sonde Coreci-Humicor, type IHRT).

\section{Stabilisation du potentiel hydrique du milieu}

Pour cette expérience, l'explant végétal est cultivé sur un support artificiel, motte de cellulose de type "Sorbarod", imbibé de milieu liquide. Ce milieu est renouvelé tous les $5 j$, ce qui évite toute fluctuation significative du potentiel hydrique $\left(\psi_{H}\right)$.

Le $\psi_{H}$ du milieu est abaissé et stabilisé, en utilisant le système précédemment décrit, à des valeurs de $-0,85 \mathrm{MPa}$ et $-1,1 \mathrm{MPa}$ par ajout respectivement de 40,7 et $81,3 \mathrm{mmol}^{-I^{-1}}$ de polyéthylèneglycol de poids moléculaire $600 \mathrm{~g}$. $\mathrm{mol}^{-1}$ (PEG 600).

\section{Mesures des paramètres hydriques}

Le poids de matière fraîche (PMF), le poids de matière sèche (PMS), la teneur en eau (TE) et la teneur en eau relative (TER) sont mesurés sur 8 échantillons représentatifs pour chaque traitement.

La $T E R$ * représente le rapport entre le poids d'eau d'un cal en culture et son poids d'eau maximal en pleine turgescence. Le PMF maximal $\left(P M F_{\mathrm{s}}\right)$ est obtenu en laissant séjourner le cal $24 \mathrm{~h}$ dans une boite de Pétri entre 2 épaisseurs de papier filtre imbibé d'eau.

Les mesures de $\psi_{H}$ sont réalisées sur un microvoltmètre au point de rosée (HR33 type Wescor, logan USA). Les échantillons (cals ou milieux de culture) sont laissés 3 h 30 (temps nécessaire à l'obtention d'un équilibre entre la pression partielle de vapeur d'eau de l'échantillon et celle de la chambre de mesure) dans une chambre à échantillon (Wescor thermocouple hygrometer sample chamber C51). La mesure au point de rosée est effectuée après un refroidissement de $15 \mathrm{~s}$. Le microvoltmètre est calibré contre des standards de $\mathrm{NaCl}$ en bars à $20^{\circ} \mathrm{C}$ (Lang, 1967).

\section{Analyses minérales}

La minéralisation des cals par voie sèche permet les dosages du calcium et du magnésium, par absorption atomique, et du potassium, par photométrie de flamme. L'azote soluble est dosé par la méthode colorimétrique de Berthelot modifiée par Fallavier (1974), sur des extraits obtenus par traitement à l'acide chlorhydrique $\mathrm{N} / 10$ pendant $74 \mathrm{~h}$.

Le potassium et le phosphore des milieux gélosés de culture sont dosés respectivement par photométrie de flamme et par la méthode colorimétrique de Kitson et Mellon (1944) après minéralisation. L'azote du milieu de culture est sous forme de nitrate et d'ammonium. Le milieu est dilué 50 fois dans l'eau bidistillée puis filtré. L'ammonium est dosé par colorimétrie (Fallavier, 1974) puis, sur le même filtrat, on quantifie les nitrates par la méthode colorimétrique de Griesse modifiée par Burdin et Egoumenides (1973).

La quantité d'élément minéral absorbée par cal $\left(E M_{\text {abs }} /\right.$ cal) ou par $\mathrm{g}$ de matière sèche est calculée à partir de celle disparue dans le milieu de culture pour chaque élément minéral et en fonction du nombre ou de la masse de cals cultivés par tube, tout en tenant compte de l'évaporation du milieu.

\section{Paramètres morphologiques}

Le taux d'embryogenèse somatique représente le pourcentage de cals portant des structures embryogènes visibles à l'œil nu (proembryons ou embryons globulaires) définies histologiquement (Michaux-Ferrière et Carron, 1989). Le taux de brunissement est le pourcentage de cals brunis ou en partie nécrosés.

\section{RÉSULTATS}

Le tégument interne de la graine d'hévéa, tel qu'il est utilisé comme explant, est un tissu particulièrement hydraté ( $T E=92 \%$ ) (tableau I). Cependant, sa teneur en eau

\footnotetext{
* TER $=(P M F-P M S) /\left(P M F_{s}-P M S\right)$
} 
chute rapidement pour se maintenir à $86 \%$ durant la callogenèse. Cette chute tient au fait que l'explant possède un $\psi_{H}$ nettement plus élevé $(-0,4 \mathrm{MPa})$ que celui du milieu de culture sur lequel il est déposé $(-0,9$ $\mathrm{MPa}$ ).

Le gradient de $\Psi_{H}$ reste défavorable à une bonne alimentation hydrique de l'explant pendant environ $10 \mathrm{j}$. Par la suite, le $\Psi_{H}$ de l'explant tend vers celui du milieu de culture et l'absorption devient alors possible.

Cette égalisation des $\psi_{H}$ de l'explant et du milieu se réalise principalement par une perte en eau de l'explant initial, puisque il n'y a pas de croissance du cal (exprimée en PMS) avant le $10^{\mathrm{e}} \mathrm{j}$ de culture (tableau I). Après ce temps de latence, l'ajustement du $\psi_{H}$ devient suffisant pour que la callogenèse soit effective.

Des analyses minérales effectuées sur l'explant pendant cette période, montrent qu'une désorption d'éléments minéraux accompagne effectivement le flux d'eau sortant du cal vers le milieu; la chute des teneurs en magnésium, calcium, potassium et azote soluble au cours de la première semaine en témoigne. Ces teneurs augmentent ensuite parallèlement à la croissance (fig 1).

La déshydratation partielle des explants sous une hotte à flux laminaire avant la mise en culture accélère l'initiation de la callogenèse. Un temps d'assèchement, plus de 3 fois supérieur au temps habituel de mise en culture de l'explant, stimule

Tableau I. Évolution des paramètres hydriques du matériel végétal pendant la phase de callogenèse $\left(J_{0}-J_{23}\right)$ : Poids de matière sèche (PMS) et teneur en eau (TE) de l'explant $\left(J_{0}\right)$ et du cal. Potentiel hydrique $\left(\psi_{H}\right)$ de l'explant, du cal et du milieu.

\begin{tabular}{ccccc}
\hline $\begin{array}{c}\text { Temps de culture } \\
(j)\end{array}$ & $\begin{array}{c}\text { PMS } \\
(m g)\end{array}$ & $\begin{array}{c}\text { TE } \\
(\%)\end{array}$ & Cal $\psi_{H}$ (MPa) & Milieu \\
\hline & & & & \\
0 & $2,9 \pm 0,1$ & $91,8 \pm 0,3$ & $-0,43 \pm 0,06$ & $-0,9 \pm 0,13$ \\
10 & $2,5 \pm 1,6$ & $86,2 \pm 1,1$ & $-0,75 \pm 0,03$ & - \\
23 & $20,1 \pm 7,9$ & $86,2 \pm 1,3$ & $-0,8 \pm 0,21$ & $-0,8 \pm 0,21$ \\
\hline
\end{tabular}

Tableau Il. Comparaison des croissances des cals à $J_{46}$, en poids de matière fraîche (PMF), et comparaison des taux de brunissement $(C B)$ et d'embryogenèse (CE) des cals à $J_{46}$ en fonction du temps d'assèchement de l'explant à $J_{0}$.

\begin{tabular}{ccccl}
\hline $\begin{array}{c}\text { Temps } \\
\text { d'assèchement } \\
(s)\end{array}$ & Effectif & PMF & $C B$ & CE \\
& & $(m g)$ & $(\%)$ & $(\%)$ \\
\hline 20 & 104 & $290 \pm 62$ & 26 & 0 \\
90 & 132 & $320 \pm 83$ & 18 & 4,7 \\
300 & 104 & $460 \pm 79$ & 9 & 6,3 \\
600 & 100 & $451 \pm 51$ & 9 & 8 \\
\hline
\end{tabular}




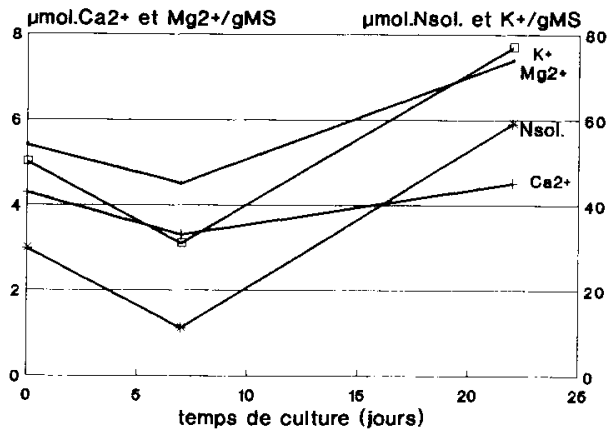

Fig 1. Évolution des teneurs en potassium (K), magnésium $(\mathrm{Mg})$, azote soluble $\left(\mathrm{N}_{\mathrm{sol}}\right.$ ) et calcium (Ca) des cals pendant la phase de callogenèse $\left(\mathrm{J}_{0}-\mathrm{J}_{23}\right)$.

l'augmentation du PMF des cals à $J_{46}$ de plus de $50 \%$ (tableau II). Ainsi, on limite le brunissement des cals et stimule la formation de proembryons.

L'humidité relative du récipient influence nettement les $\psi_{H}$ du milieu et du cal (fig 2A). La chute du $\psi_{H}$ du milieu de $J_{23}$ à $J_{46}$, pendant la phase d'induction des embryons, est étroitement liée au taux de déshydratation du milieu de culture indiqués sur la figure $2 \mathrm{~A}$. Le $\psi_{H}$ des cals suit globalement l'évolution de celui du milieu sur lequel les cals sont cultivés, tout en restant toujours un peu plus négatif.

Les TE et TER des cals sont d'autant plus faibles que l'HR de l'atmosphère de culture diminue (fig 2B). Une forte humidité limite le pourcentage de cals brunis tout en favorisant la formation de cals embryogènes (fig 2C).

En fait, une analyse plus fine du matériel végétal, effectuée dans des conditions standard de culture, montre que seul le $\psi_{H}$ des cals non embryogènes chute à une valeur de $-1,6 \mathrm{MPa}$ alors que celui des cals embryogènes se maintient à un fort
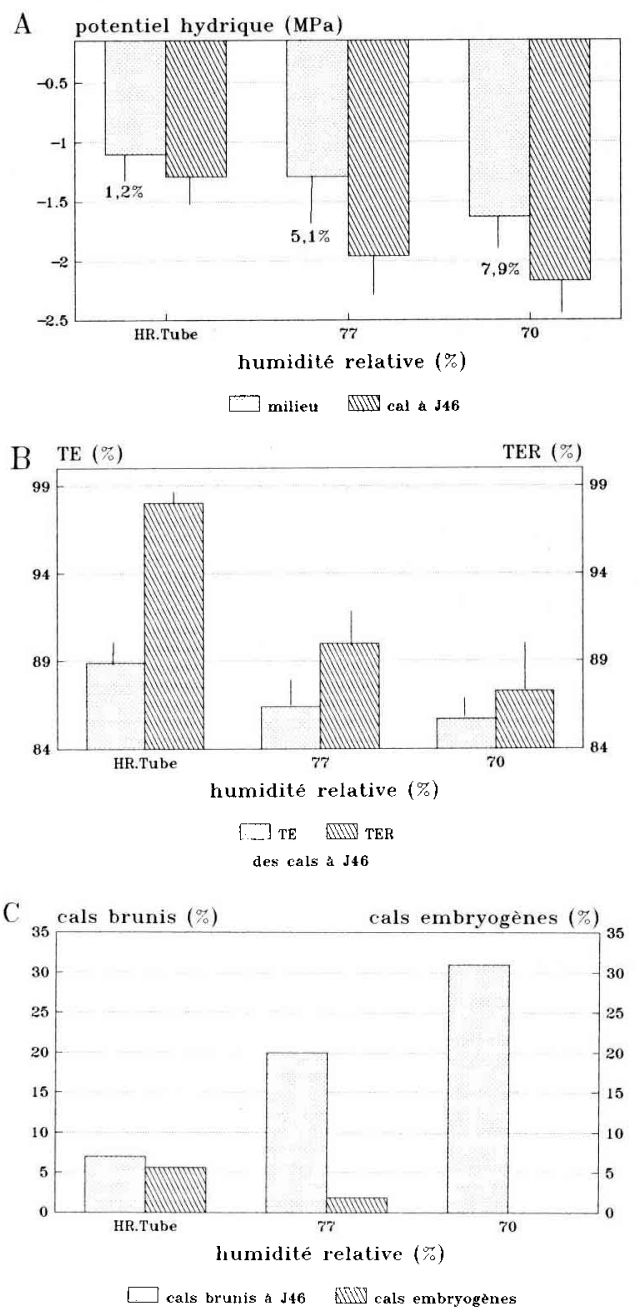

Fig 2. influence de l'humidité relative des récipients de culture sur : $\mathbf{A}$. Le potentiel hydrique $\left(\psi_{H}\right)$ des cals et des milieux de culture à $J_{46}$, (les pourcentages, sous les histogrammes des potentiels hydriques du milieu de culture représentent la déshydratation du milieu gélifié). B. La teneur en eau (TE) et la teneur en eau relative (TER) des cals à $\mathrm{J}_{46}$. C. Le taux de brunissement et le taux d'embryogenèse à $J_{46}$. “HR tube" représente l'humidité relative du récipient standard de culture, proche de la saturation. L'effectif utilisé est de 140 cals par traitement, répartis en 7 récipients de culture. 
niveau, comparable à celui du cal formé à $\mathrm{J}_{23}$ (fig 3).

De nouvelles expériences ont donc été réalisées afin de vérifier cette relation en intervenant sur le $\psi_{H}$ des cals par l'intermédiaire d'autres paramètres de culture tels que la stabilisation du $\psi_{H}$ du milieu ou la modification de la composition hormonale.

Tout d'abord, on observe que la stabilisation de la composition du milieu, obtenue par un renouvellement fréquent du milieu liquide, stimule fortement l'embryogenèse; cet effet est là encore associé à une diminution du taux de cals brunis et une augmentation de la TER (tableau III).

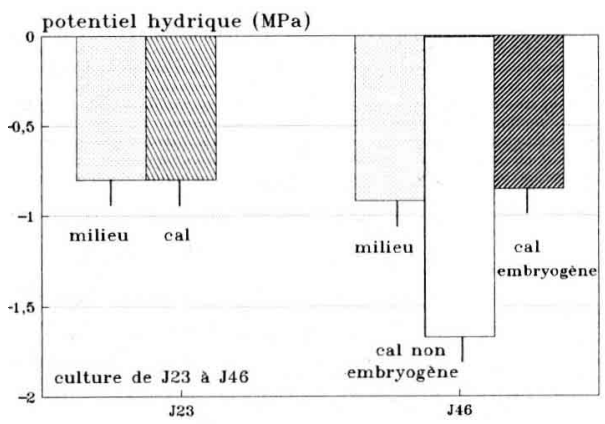

Fig 3. Évolution des potentiels hydriques $\left(\psi_{H}\right)$ du milieu et des cals (non embryogènes et embryogènes) lors de la phase d'induction de l'embryogenèse $\left(J_{23}-J_{46}\right)$. Chaque mesure est répétée sur 4 cals.
Pour distinguer plus directement l'effet propre de la stabilisation du $\psi_{H}$ du milieu par rapport à celui du renouvellement du milieu, on fait varier le $\psi_{H}$ du milieu en l'abaissant par des apports de PEG 600.

Les résultats obtenus corroborent tout à fait les précédents : le renouvellement des milieux ayant un faible $\psi_{H}(-0,85$ et $-1,1$ $\mathrm{MPa}$ ), n'est pas favorable à l'embryogenèse, tandis que le maintien du $\psi_{\mathrm{H}}$ du milieu à une valeur peu négative $(-0,7 \mathrm{MPa})$ la stimule fortement et s'oppose au brunissement des cals (fig 4A). II permet en outre l'acquisition par le cal de valeurs de $T E$ et surtout de TER plus élevées (fig 4B).

II est également possible de stimuler l'embryogenèse somatique par un faible apport d'ABA (10-7 mol. I $\left.^{-1}\right)$ dans le milieu au cours des deuxième et troisième phases de culture. Ce complément hormonal stimule la croissance des cals (le PMF est doublé à $J_{46}$ ) mais surtout, il prolonge considérablement l'activité mitotique du cal qui reste peu sensible au phénomène de brunissement (tableau IV) et conserve des potentialités embryogènes au-delà de $J_{70}$.

Une fois de plus, les traitements les plus embryogènes possèdent (quel que soit le temps de culture) une TER et un $\psi_{H}$ élevés (tableau IV). Par contre, la TE n'apparaît liée ni à l'acquisition ni à la perte du potentiel embryogène. La chute du pour-

Tableau III. Effet de la stabilisation de la composition du milieu de culture sur la teneur en eau (TE), la teneur en eau relative (TER) et les taux de brunissement (CB) et d'embryogenèse (CE) des cals à $\mathrm{J}_{46}$. Effectif de 168 cals par traitement.

\begin{tabular}{ccc}
$\begin{array}{c}\text { Paramètres du cal } \\
\text { à } J_{46}(\%)\end{array}$ & $\begin{array}{c}\text { Milieu } \\
\text { non renouvelé }\end{array}$ & $\begin{array}{c}\text { Milieu } \\
\text { renouvelé }\end{array}$ \\
\hline$T E$ & $86,7 \pm 1,4$ & $87,4 \pm 1,8$ \\
$T E R$ & $88,7 \pm 1,7$ & $93,4 \pm 2$ \\
$C B$ & 16 & 5 \\
$C E$ & 5 & 20 \\
\hline
\end{tabular}


A TE (\%) TER (\%)

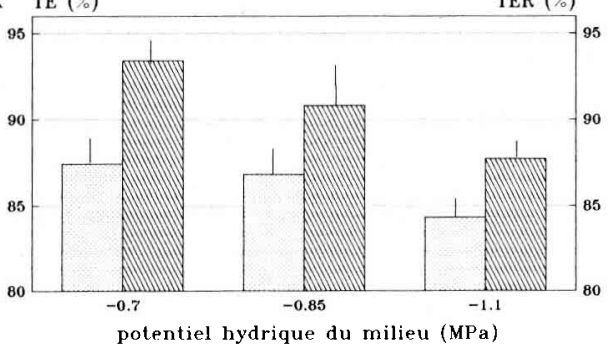

LE TEN TER

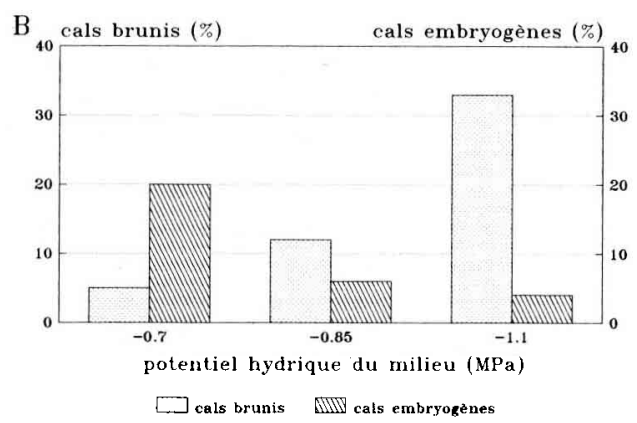

Fig 4. Effet de la diminution du potentiel hydrique $\left(\psi_{H}\right)$ du milieu par des apports de PEG 600 dans le milieu de culture sur: A. La teneur en eau (TE) et la teneur en eau relative (TER) des cals à $J_{46}$. B. Le taux de brunissement et d'embryogenèse des cals à $J_{46}$. L'effectif utilisé par traitement est de 560 cals. centage de cals embryogènes à $J_{70}$ dans le cas d'une culture en présence de $10^{5} \mathrm{~mol}^{-1} \mathrm{I}^{-1}$ d'ABA s'accompagne ainsi d'une baisse de la TER et du potentiel hydrique des cals, mais pas de la diminution de la $T E$.

L'analyse de la consommation en éléments minéraux majeurs du milieu de culture (azote, phosphore, potassium) réalisée pour cette dernière expérience, met nettement en relief l'efficacité du traitement à faible concentration d'ABA $\left(10^{-7} \mathrm{~mol}^{\prime} \mathrm{I}^{-1}\right)$ par rapport aux 2 autres traitements (fig $5 A, B, C)$. Cette consommation, ramenée à la quantité absorbée en EM par g de matière sèche, met en évidence une continuité dans l'absorption de $N, K$ et $P$ chez les cals cultivés en présence de $10^{-7} \mathrm{~mol}^{-1} \mathrm{I}^{-1}$ d'ABA par rapport au 2 autres traitements (fig 5D, E, F). Dans la seconde phase de culture de $J_{23}$ à $J_{46}$, l'absorption d'éléments minéraux par $\mathrm{g}$ de matière sèche de cal augmente en fonction de la concentration en $A B A$. Lors de la culture suivante, seuls les cals du traitement $A B A 1^{-7}$ mol..$^{-1}$ conservent un bon niveau d'absorption pour les 3 éléments minéraux, notamment vis-à-vis du phosphore pour lequel la différence est remarquable.

Tableau IV. Influence d'un apport d'ABA, dans le milieu de culture entre $J_{23}$ et $J_{70}:$ - sur la croissance des cals (exprimée en mg de matière fraîche, $P M F$, sur la teneur en eau (TE), sur la teneur en eau relative (TER) et sur le potentiel hydrique $\left(\psi_{H}\right)$ des cals à $J_{46}$ et à $J_{70}$; - sur le taux de cals brunis (CB) et de cals embryogènes (CE) en fin de phase d'induction $\left(\mathrm{J}_{46}\right)$ et de phase de développement $\left(J_{70}\right)$ des embryons somatiques. Effectif de 216 cals par traitement.

\begin{tabular}{clrrrrrr}
\hline $\begin{array}{c}\text { Temps } \\
(j)\end{array}$ & $\begin{array}{l}A B A \\
(M)\end{array}$ & $\begin{array}{c}\text { PMF } \\
(\mathrm{mg})\end{array}$ & $\begin{array}{c}C B \\
(\%)\end{array}$ & $\begin{array}{c}\text { CE } \\
(\%)\end{array}$ & $\begin{array}{l}\text { TE } \\
(\%)\end{array}$ & $\begin{array}{c}\text { TER } \\
(\%)\end{array}$ & $\begin{array}{c}\psi_{H} \\
(M P a)\end{array}$ \\
\hline \multirow{4}{*}{46} & 0 & $84 \pm 17$ & 0 & 5 & $87 \pm 1,9$ & $91,4 \pm 0,9$ & $-9,5 \pm 1,9$ \\
& $10^{-7}$ & $162 \pm 67$ & 0 & 26 & $85,1 \pm 1,8$ & $93,2 \pm 0,6$ & $-9,1 \pm 1,7$ \\
& $10^{-5}$ & $99 \pm 25$ & 1 & 23 & $88,1 \pm 1,5$ & $92,9 \pm 1,2$ & $-10,3 \pm 1,4$ \\
70 & 0 & $77 \pm 19$ & 81 & 3 & $88,5 \pm 1,5$ & $92,1 \pm 0,9$ & $-12,7 \pm 0,4$ \\
& $10^{-7}$ & $162 \pm 47$ & 11 & 40 & $85,2 \pm 1,5$ & $94,0 \pm 0,9$ & $-9,6 \pm 0,4$ \\
& $10^{-5}$ & $64 \pm 24$ & 94 & 6 & $87,6 \pm 2,1$ & $91,2 \pm 0,5$ & $-11,9 \pm 0,7$ \\
\hline
\end{tabular}



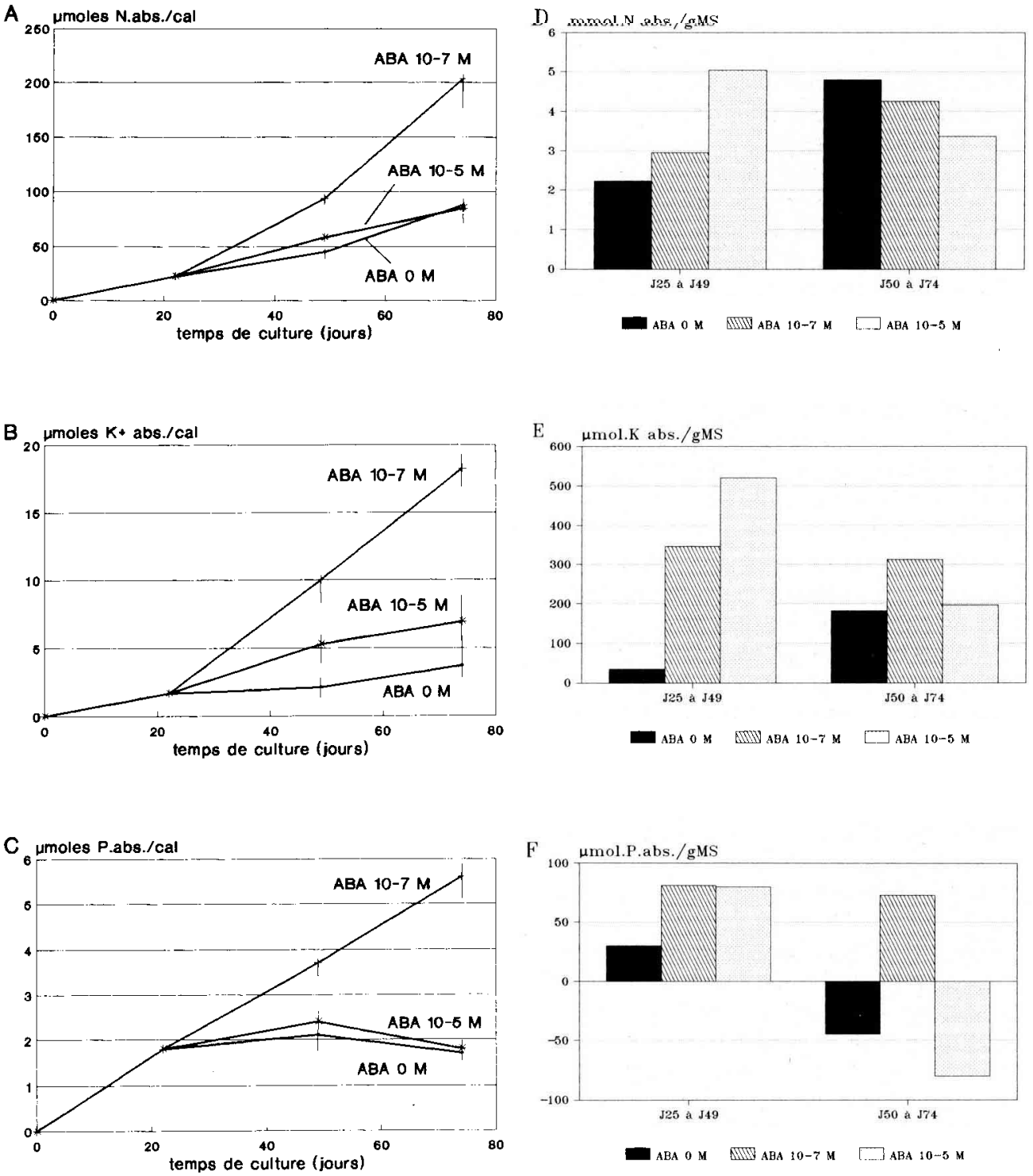

Fig 5. Consommation en éléments minéraux en fonction de l'apport d'ABA : - exprimée en $\mu \mathrm{mol}$ consommées par cal, au cours des 3 cultures successives: A. Azote total du milieu de culture (nitrate + ammonium); B. Potassium du milieu de culture; C. phosphate du milieu de culture. - exprimée en $\mu \mathrm{mol}$ consommées par $\mathrm{g}$ de matière sèche, au cours des phases d'induction et de développement des embryons : D. azote total du milieu de culture (nitrate + ammonium); E. potassium du milieu de culture; F. phosphate du milieu de culture. 


\section{DISCUSSION}

Personne n'oserait contester l'importance de l'eau dans les phénomènes biologiques, donc en culture in vitro; néanmoins très peu de données existent aujourd'hui, susceptibles de servir de référence en la matière. Aussi, les résultats présentés ici ont-ils pour premier objectif de quantifier un certain nombre de paramètres hydriques liés au végétal ou au milieu lui-même et de suivre leur évolution au cours de la culture. Leur analyse nous permet de mieux comprendre l'influence du milieu ou des conditions de culture sur le végétal et de mettre en évidence des relations entre certaines caractéristiques du cal et ses capacités de régénération.

L'assèchement partiel de l'explant est favorable à l'initiation de la callogenèse, en permettant un réajustement préalable de l'état hydrique du matériel végétal par rapport à celui du milieu de culture sur lequel il sera déposé. Ainsi l'absorption des éléments du milieu et la prolifération cellulaire peuvent démarrer très rapidement, au lieu d'être différées d'environ dix jours; ce temps de latence ne pouvant qu'engendrer une dégradation partielle des tissus. $\mathrm{Ce}$ résultat logique a posteriori ne l'était pas a priori puisque l'on considère généralement la mise en culture comme un stress important pour l'explant, que l'on doit chercher à limiter au maximum. L'ajustement osmotique que réalise l'explant, durant les 10 premiers jours de culture, apparaît donc comme un stress bien plus défavorable qu'un assèchement brutal appliqué sous forme de prétraitement.

Lors de la culture, l'expression de l'embryogenèse somatique est très étroitement associée à une forte valeur de la TER et à un fort $\psi_{H}$ des tissus du cal. L'observation morphologique montre généralement dans ce cas une meilleure croissance mais surtout une plus longue survie des cals, se caractérisant par l'absence de brunissement. Cette observation se révèle, au niveau cytologique, être la conséquence du maintien d'une forte prolifération des cellules méristématiques à la périphérie du cal associée à une faible densité de cellules chargées en phénols et de type parenchymateux (Michaux-Ferrière et Carron, 1989). La forte TER serait donc le reflet de cette intense activité métabolique, en accord avec la théorie de Sinclair et Ludlow (1985), pour qui ce paramètre quantifie le mieux l'importance du stress hydrique sur le matériel végétal. On comprend donc l'intérêt de maintenir une humidité relative élevée dans le récipient de culture et éventuellement de stabiliser le $\psi_{H}$ du milieu, conditions facilitant le maintien d'un état hydrique optimal pour l'embryogenèse chez le cal d'hévéa. De faibles $\psi_{H}$ sont observés chez les cals des traitements peu ou pas embryogènes $(70 \% \mathrm{HR}$ atmosphère ou $\psi_{H}$ milieu de $-1,1 \mathrm{MPa}$ ). Cette inhibition de l'embryogenèse somatique par une diminution du $\psi_{H}$ du milieu de culture s'oppose aux résultats observés sur le tabac (Imamura et Harada, 1980), sur le papayer (Litz et Conover, 1983), sur l'épicéa commun (Von Arnold, 1987), ou sur le blé (Brown et al, 1989) où elle s'avérait favorable à la formation d'embryons somatiques. Les faibles $\psi_{H}$ chez les cals d'hévéa témoignent vraisemblablement de l'existence d'un stress hydrique, ces derniers ayant dû pour survivre réaliser un ajustement de leur $\psi_{H}$ incompatible avec une évolution embryogène.

Le maintien d'un fort $\psi_{H}$ et d'une TER élevée peut également être obtenu par incorporation d'ABA $\left(10^{-7} \mathrm{~mol}^{-1} \mathrm{I}^{-1}\right)$ dont on re-trouve le rôle dans l'amélioration de la résistance aux stress hydriques (Loveys et al, 1975; Guerrero et Mullet, 1986; Bartels et al, 1988). Néanmoins, selon les simples lois de diffusion, il apparaît que l'absorption des éléments minéraux ne devrait pas être favorisée au niveau des cals embryo- 
gènes dont le $\psi_{H}$ reste très voisin de celui du milieu alors que le $\psi_{H}$ plus faible des cals non embryogènes rendrait théoriquement cette absorption plus facile. L'analyse de la consommation des éléments minéraux du milieu par le cal, nous montre qu'il n'en est rien, au contraire. On a donc probablement affaire à une absorption dépendante de l'état physiologique des cals. En outre, des gradients de $\psi_{H}$ très faibles (inférieurs à $0,05 \mathrm{MPa}$ ) sont généralement suffisants pour soutenir la croissance des tissus végétaux (Cosgrove, 1984). Newton et al (1989b) montrent eux aussi, que le $\psi_{H}$ des cals de Pinus taeda s'équilibre avec le fort $\psi_{H}$ du milieu de culture. Cet ajustement, qui ne s'oppose pas à l'accumulation de solutés, est permis par l'absorption d'eau du milieu. Cette situation s'apparente donc tout à fait à celle des cals embryogènes d'hévéa.

\section{CONCLUSION}

Cette étude met en évidence que le cal d'hévéa est un système très sensible aux fluctuations de son environnement. La régulation hydrique propre au cal apparaît très limitée, cela étant dû à la simplicité de son ultrastructure (Michaux-Ferrière et Carron, 1989). N'ayant pas mesuré le potentiel osmotique $\left(\psi_{\mathrm{s}}\right)$ des cals lors de ces expériences, nous n'avons pu calculer leur potentiel de turgescence qui nous aurait permis de déterminer s'ils étaient capables d'ajustement osmotique. Ce phénomène fut observé sur des cultures de cals lors d'un stress salin (Chandler et al, 1987) ou sur des suspensions cellulaires de tomate lors d'un stress hydrique (Handa et al, 1982). À l'opposé, cet ajustement osmotique n'existe pas chez les cals de Pinus taeda (Newton et al, 1989b). II apparaît donc capital chez l'hévéa, de contrôler rigoureusement l'environnement hydrique du cal (hygrométrie de l'atmosphère et disponibilité en eau du milieu).

L'embryogenèse somatique de l'hévéa dépend de phénomènes indéniablement plus complexes que l'approche réalisée ici. Pourtant, il apparait clairement que les facteurs de l'environnement de culture interagissent avec un statut hydrique particulier dans le contrôle du processus d'embryogenèse somatique chez l'hévéa.

Différents paramètres hydriques tels que $\psi_{H}, \psi_{S}$ et TE sont directement impliqués dans la réussite de l'organogenèse chez le riz et le tabac (Brown et Thorpe, 1980; Chandler et al, 1987; Lai et Liu, 1988). Mais, à notre connaissance, c'est la première fois que de tels paramètres sont reliés au processus d'embryogenèse somatique : $\psi_{\mathrm{H}}$ tissulaire et TER semblent étroitement associés à la formation d'embryons somatiques chez l'Hevea brasiliensis. Les conditions de mise en culture, l'HR de l'atmosphère et le $\psi_{H}$ du milieu apparaissent alors comme des facteurs limitants car ils interagissent avec les paramètres hydriques du cal. Nos conclusions s'ajoutent donc à celles obtenues en organogenèse pour élever l'eau au rang d'un paramètre à contrôler en culture in vitro.

\section{REMERCIEMENTS}

Nous tenons à remercier Monsieur Berger qui nous a accueillis dans son laboratoire (CEPECNRS, Montpellier) pour réaliser les mesures de potentiel hydrique.

\section{RÉFÉRENCES}

Abou-Mandour AA, Hartung W (1986) The effect of abscissic acid and increased osmotic potential of the media on growth root regeneration of Zea mays callus. J Plant Physiol 122, 139-145 
Auboiron $E$, Carron MP, Michaux-Ferrière N (1990) Atmospheric gases and ethylene synthesis in somatic embryogenesis of Hevea brasiliensis. Plant Cell Tissue and Organ Cult 21, 31-37

Bartels D, Singh M, Salamini F (1988) Onset of desiccation tolerance during development of barley embryo. Planta 175, 485-492

Brown DCW, Thorpe TA (1980) Changes in water potential and its components during shoot formation in tobacco callus. Physiol Plant 49, 83-87

Brown C, Brooks FJ, Pearson D, Mathias RJ (1989) Control of embryogenesis in immature wheat embryo callus using increased medium osmolarity and abscissic acid. $J$ Plant Physiol 133, 727-733

Burdin S, Egoumenides C (1973) Détermination de l'azote ammoniacal et nitrique dans les sols et les eaux. Méthodes de dosage colorimétrique. Agron Trop 28, 1193-1199

Carron MP, Enjalric F (1985) Embryogenèse somatique à partir du tégument interne de la graine d'Hevea brasiliensis (Kunth) Müll Arg. C R Acad Sci (Paris) 300, 653-658

Carron MP, Enjalric F, Lardet L, Deschamps A (1989) Rubber (Hevea brasiliensis Müll Arg). In: Biotechnology in Agriculture and Forestry, 5. Trees /I (Bajaj YPS, ed) Springer-Verlag, Berlin, 222-245

Chandler SF, Ragolsky E, Pua EC, Thorpe TA (1987) Some morphogen effects of sodium sulfate on tobacco callus. Plant Cell Tissue and Crgan Cult 11, 14t-150

Chen C, Chen F, Chien C, Wang C, Chang S, Hsu H, Ou S, Ho Y, Lu T (1979) A procesS of obtaining pollen plants of Hevea brasiliensis Muell-Arg. Sci Sin XXII, 81-90

Compagnon $P$ (1986) Le caoutchouc naturel. GP Maisonneuve, Larose, Paris

Cosgrove $D$ (1984) Hydraulic aspects of plant growth. What's New in Plant Physiol 15, 5-8

El Hadrami I, Michaux-Ferrière N, Carron MP, D'Auzac $J$ (1989a) Les polyamines, facteur limitant possible de l'embryogenèse somatique chez l'Hevea brasiliensis. CR Acad Sci (Paris) 308, 205-211

El Hadrami I, Carron MP, D'Auzac J (1989b) Variabilité clonale du potentiel embryogène chez l'Hevea brasiliensis; relations avec les polyamines (PA) et les peroxydases (PO) des cals. CR Séances Acad Sci (Paris) 308, 299-305

Fallavier $P(1974)$ Mise au point du dosage ammoniacal par colorimétrie automatique. CR de Contrat de Recherche DGRST France, "Bilan de l'azote", 100-127

Guerrero PM, Mullet JE (1989) Increased abscissic acid biosynthesis during plant dehydratation required transcription. Plant Physiol $80,588-591$

Greenspan L (1977) Humidity fixed points of binary satured aqueous solutions. Journal of Research of the National Bureau of Standards, Physics and Chemistry 81, 89-96

Hammersley-Straw DHR, Thorpe TA (1988) Use of osmotic inhibition in studies of shoot formation in tobacco callus cultures. Bot Gaz 149, 303-310

Handa AK, Bressan RA, Handa S, Hasegawa PM (1982) Charactéristics of cultured tomato cells after prolonged exposure to medium containing polyethylene glycol. Plant Physiol $69,514-521$

Imamura J, Harada H (1980) Effect of abscissic acid and water stress on the embryo and plantlet formation in another culture of Nicotiana tabacum CV Sansun. $Z$ Pflanzenphysiol 91, 255-266

Kimball SL,Beversdorf WD, Bingham ET (1975) Influence of osmotic potential on the growth and development on soybean tissue cultures. Crop Sci 15, 750-752

Kitson RE, Mellon MG (1944) Colorimetric determination of phosphorus as molybdivanadophosphoric acid. Ind Eng Chem 16, 379-383

Lai KL, Liu LF (1988) Increased plant regeneration frequency in water stressed rice tissue cultures. Jpn J Crop Sci 57, 553-557

Lang ARG (1967) Osmotic coefficients and water potentials of sodium chloride solutions from 0 to $40^{\circ} \mathrm{C}$. Aust J Chem 20, 2017-2023

Litz RE, Conover RA (1983) High frequency somatic embryogenesis from carica suspension cultures. Ann Bot 51, 683-686

Loveys BR, Brien CJ, Kriedemann PE (1975) Biosynthesis of abscissic acid under osmotic stress: studies based on a dual labelling technique. Physiol Plant 39, 166-170

Michaux-Ferrière N, Carron MP (1989) Histology of early somatic embryogenesis in Hevea brasiliensis: The importance of the timing of 
subculturing. Plant Cell, Tissue Organ Cult $19,243-256$

Murashige T, Skoog F (1962) A revised medium for rapid growth and bioassays with tobacco tissue cultures. Physiol Plant 15, 473-497

Newton RJ, Puryear JD, Sen S (1989a) Water status and growth of loblolly pine (Pinus taeda L) callus. Plant Cell, Tissue Organ Cult $16,3-13$

Newton RJ, Sen S, Puryear JD (1989b) Solute contributions to osmotic potential in loblolly pine (Pinus taeda L) callus. J Plant Physiol $134,746-750$
Sinclair TR, Ludlow MM (1985) Who taught plants thermodynamics? The unfulfilled potential of plant water potential. Aust J Plant Physiol 12, 213-217

Von Arnold S (1987) Improved efficiency of somatic embryogenesis in mature embryos of Picea abies. J Plant Physiol 128, 233-244

Wan AR, Ghandimathi $H$, Rohani O, Paranjothy K (1982) Recent developments in tissue culture of Hevea. In: Tissue culture of economically important plants (Rao AN, ed) Costed, Singapore, 152-158 